Institute of Radiotherapy and Nuclear Medicine,

The National Ribat University.

\title{
ULTRASONOGRAPHY FOR DIAGNOSIS OF HYDROMETRA AND PYOMETRA (TWO CASE REPORTS)
}

(With 2 Figures)

\author{
By \\ B.H. AHMED; RUGIA J. HAMAD* \\ and RIHAB M. ABDELGHAFAR** \\ *Ministry of Agriculture, Animal Wealth and Irrigation, Khartoum State. \\ **College of Veterinary Medicine, Sudan University of Science \\ and Technology \\ (Received at 10/11/2009)
}

\section{SUMMARY}

Two cases of hydrometra and pyometra in dairy goats were reported. 2-4 years multiparous dairy Saanen and Damascus goats were scanned by ultrasonography for pregnancy diagnosis. The scanning was done using real-time scanner equipped with dual frequency $(5-7.5 \mathrm{MHz})$ micro convex transducer, while the animals were well restrained on a dorsal recumbancy. Incidentally during the routine scanning for pregnancy diagnosis, an anechoic and hypoechoic compartmentalized fluid filled uteri; with absence of fetal parts or placentomes were observed in the two does. The cases were diagnosed as hydrometra and pyometra respectively. In conclusion ultrasound was found to be an efficient tool in diagnosing the female reproductive tract disorders; in addition to that it was found a potential tool in differentiating between fluid-filled gestational sacs of normal pregnancy and abnormally fluid accumulations in the uterus such as hydrometra and pyometra.

Key words: Hydrometra, pyometra, goats, ultrasound

\section{INTRODUCTION}

Hydrometra or pseudopregnancy which is regarded as synonymous is a pathological condition of the uterus in which a septic 
fluid accumulates in the uterine lumen in the presence of a persistent corpus luteum (Hesselink 1993a and b). It forms a major cause of sub fertility in goats (Kornalijnslijper et al., 1997). Due to the a septic character of the fluid collection, no modification in the general clinical status of the animal is observed (Lega and Toniollo 1999), and hydrometra is incidentally observed during routine pregnancy diagnosis. Presence of fluids in the uterus can be readily diagnosed by transcutaenous ultrasonographic scanning of the pelvic area of the abdominal cavity (Taverne et al., 1995).

\section{MATERIALS and METHODS}

Two does (Saanen and Damascus) were subjected to routine pregnancy diagnosis. They were fed Alfa Alfa hay ad libitum and a mixture of (Wheat brand, Sesame cake, Ground nut cake and Sorghum), with free access to water and minerals blocks supplement. Animals were kept off food for 12 hours prior to scanning; however water was allowed ad libitum. The ventral abdomen was clipped and shaved carefully.

Animals were layed on their backs (dorsal docubitus), with a pillow put underneath as described previously by (Abdelghafar 2006). Sufficient amount of ultrasonic gel (Sono gel Vertriebs GMBH, Germany) was applied to the ventral abdomen prior to the scanning.

Ultrasound examination was performed on each goat using a realtime scanner (Easote Pie Medical, Holland) equipped with dual frequency $(5-7.5 \mathrm{MHz})$ micro convex probe. Images were printed in a thermal papers using video graphic printer UP-895EC (Sony- Japan).

\section{RESULTS}

In case one (Saanen Goat) a nonechogenic (i.e. black) fluid-filled compartmentalized uterus was demonstrated (Fig. 1), no fetal parts or placentomes were seen. Ultrasound guided fine needle aspirated sample was taken from the uterus and the fluid was water clear, the animal was accurately diagnosed as having a hydrometra. In case two (Damascus Goat) a hypoechoic fluid-filled compartmentalized uterus was demonstrated with a highly echogenic material which represents inflammatory cells as shown in (Fig 2a, 2b), the animal was diagnosed as having pyometra. 


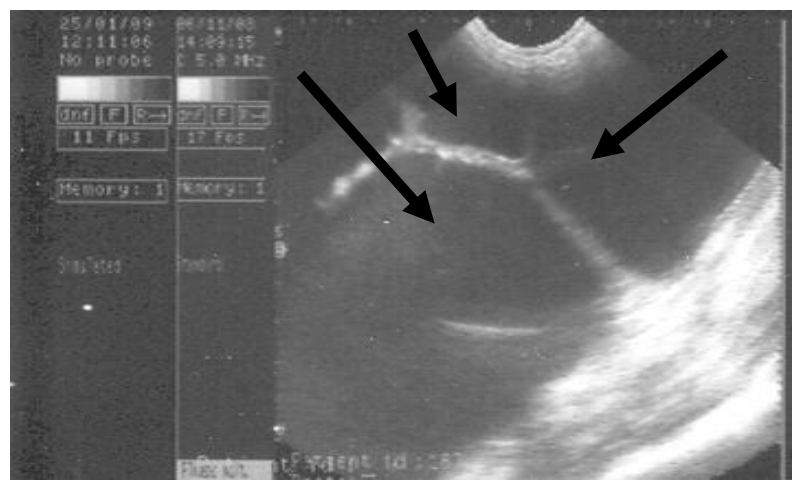

Fig. 1: Hydrometra (Realize the compartments)

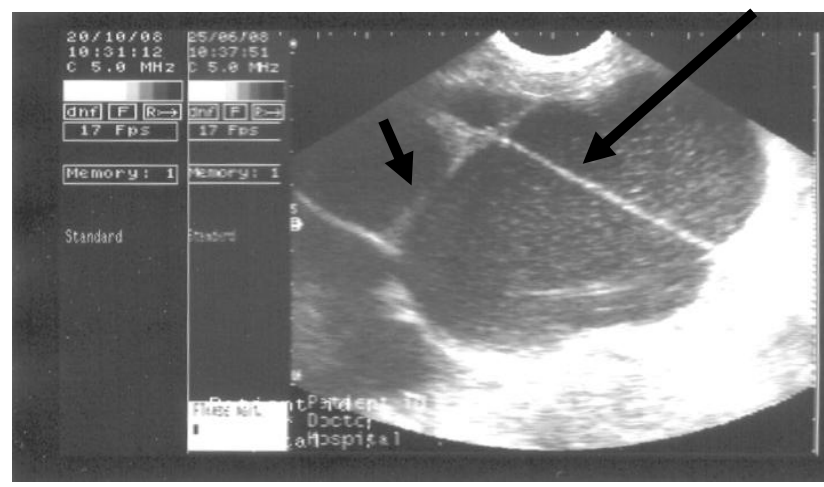

Fig. 2a: Pyometra (Realize the compartments)

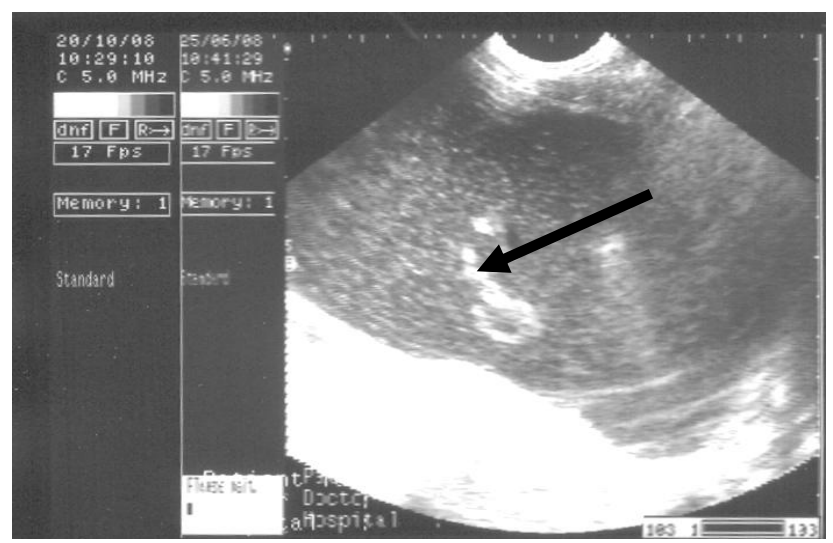

Fig. 2b: Pyometra (Realize the highly echogenic material (Arrow) 


\section{DISCUSSION}

Ultrasonography is a very suitable diagnostic tool in the examination of female genital organs in domestic mammals and it has been considered as a powerful tool in deciding line of treatment in obstetrical cases (Taverene, 1984; Chandolia et al., 2005). Diagnostically, one of the most important applications of ultrasonography in reproduction is detection and monitoring of uterine abnormalities (Griffin 1995). Two pathological conditions were diagnosed using real-time ultrasound scanning, these conditions have been diagnosed all over the world in many animal species including goats, however to the best of our knowledge this article seems to be the first of its type in the Sudan to report reproductive tract disorders in goats using ultrasound technique. Hesselink and Taverne (1994) reported that the sonographic diagnosis of hydrometra is based upon recognition of fluids in the uterus in the absence of fetuses and placentomes; and hydrometra in goats can be diagnosed easily and reliably by ultrasound scanning (Hesselink 1993a). Pyometra is an acute or chronic purulent infection of the uterus which is greatly distended by pus accumulation (Jones, et al., 1997). The fluid contains obvious reflections and its echogenicity depends on the relative amount of cellular material (Kahn 2005). Ultrasonography is widely used in many aspects of small ruminant reproduction (Russel and Goddard 1995). It has rapidly become established as one of the principal imaging techniques used in veterinary practice.

In the present study greatly distended uteri with absence of fetal parts and cotyledons would suggest hydrometra or pyometra; which were physically differentiated by the echo pattern of the accumulated fluid. Hesselink and Taverne (1994) reported that in the goat accumulation of cloudy fluid in the uterus can be associated by pathological conditions such as fetal death during early pregnancy or post partum pyometra. In this study, the uteri were thoroughly scanned and many sections were taken to ascertain that all the uterine lumen was depicted and no fetal parts or placentomes were present.

In conclusion real-time ultrasonography is an accurate, reliable and efficient method for detecting uterine pathology in non- pregnant goats. It is a very potential aid in differentiating between abnormally fluids accumulation in the uterus and the normal fluid-filled gestational sacs of normal pregnancy. 


\section{REFERENCES}

Abdelghafar, R.M. (2006): Pregnancy Diagnosis and Fetometry in Saanen Goats Using Real-time Ultrasonography. M. Sc Thesis, Sudan University of Science and Technology. pp 71.

Chandiola, R.K.; Pradeep, S.V.; Kumar, J. and Tayal, R. (2005): Comparative ultrasonographic fetal studies in goat and dog. Indian J. of Anim. Sci., 75 (9): 1054-1056.

Griffin, P.G. (1995): Equine Reproductive Ultrasonography in: Veterinary Ultrasonography, Goddard, P.J. Cab International Wallingford Oxon OX108DE, UK. pp 165-184.

Hesselink, J.W. (1993a): Incidence of hydrometra in dairy goats. The Vet. Rec. 132: 110-112.

Hesselink, J.W. and Taverne, M.A. (1994): Ultrasonography of the uterus of the goat. Veterinary Quarterly (16): 1, 41-51.

Hesselink, J.W. (1993b): Hydrometra in dairy goats: Reproductive performance after treatment with prostaglandins. Vet. Rec. 133: 186-187.

Jones, T.C.; Hunt, R.D. and King, N.W. (1997): Genital system in: Veterinary Pathology. $6^{\text {th }}$ edition, Williams and Wilkins Company pp 1149-1221.

Kahn, W. (2005): Ultrasonography in Sheep and Goats In: Veterinary Reproductive Ultrasonography, Schlutersche Verlagsgesellschaft $\mathrm{mbH}$ and Co. KG, Hans-Bockler- Allee 7, 30173, Hannover. pp. 187-210.

Kornalijnslijper, J.E.; Beveres, M.M.; Van Oard, H.A. and Taverne, M.A. (1997): Induction of hydrometra in goats by means of active immunization against prostaglandin F2 $\alpha$. Anim. Reprod. Sci., 46 (1-2): 109-122.

Lega, E. and Toniollo, G.H. (1999): Hydrometra in goats. Report of a case in Capra hircus. Brazilian Journal of Animal Reproduction 23: 446-447.

Russel, A.J. and Goddard, P.J. (1995): Small Ruminant Reproductive Ultrasonography: In Goddard, P.J. Veterinary Ultrasonography, Cab International Wallingford Oxon OX108DE, UK. Pp 257-274. 
Taverene, M.A. (1984): The use of linear array real-time echography in veterinary obstetrics and gynecology. Tijdschr Diergeneeskd, 15 (12): 494-506.

Taverne, M.A.; Hesselink, J.W.; Beveres, M.M.; Van Oard, H.A. and Kornalijnslijper, J.E. (1995): Etiology and endocrinology of Pseudopregnancy in the Goat, Reprod. Dom. Anim. 30, 228-230. 